\title{
In Appreciation of Professor Robert H. Wood
}

\author{
Emmerich Wilhelm
}

Published online: 21 January 2015

(C) Springer Science+Business Media New York 2015

This special issue of the Journal of Solution Chemistry is dedicated to Professor Robert H. Wood on the occasion of his 80th birthday. It contains work presented at the 68th Calorimetry Conference in Atlantic City, New Jersey, USA, August 18-22, 2013, that is in the symposium on Aqueous Solutions, Fluid Mixtures and Polymers-A Tribute to Robert $H$. Wood on the Occasion of His 80th Birthday. The different scientific topics of the lectures made for an interesting and memorable symposium for all in attendance; it was highly appreciated by Professor Wood, though unexpected health problems unfortunately precluded his participation. Because of Bob Wood's prominent role in solution chemistry, a Festschrift in the Journal of Solution Chemistry is most appropriate, and I was greatly pleased by the enthusiastic acceptance of my suggestions concerning Symposium and Festschrift by Professor Jean-Pierre E. Grolier (Université Blaise Pascal, Clermont-Ferrand, France), Symposium Co-Organizer, by Professor David P. Remeta (Rutgers University, New Brunswick, NJ, USA), Program Chair for CALCON 2013, and by the Editors-in-Chief of the Journal of Solution Chemistry, Professor Joseph A. Rard and Professor W. Earle Waghorne.

Bob Wood's interest in the physical chemistry of solutions now spans about five decades and is documented by his more than 150 published technical papers, the majority of which is devoted to the physical chemistry of aqueous solutions of electrolytes and nonelectrolytes. When the focus is on water as solvent, one has to realize that water is not only the most abundant substance on the surface of the earth, it is also the only substance on earth occurring naturally in all three states of matter. Water is important for the structure, the stability and the function of biomolecules, that is to say, it has a controlling influence on biochemical processes and is thus a prerequisite for the emergence of life as we know it.

Professor Wood's scientific work may be subdivided roughly into six topics listed below. For each topic I have included one or more representative publications:

\footnotetext{
E. Wilhelm $(\bowtie)$

Institute of Physical Chemistry, University of Wien (Vienna), Währinger Straße 42,

1090 Wien (Vienna), Austria

e-mail: emmerich.wilhelm@univie.ac.at
} 
- Density measurements on aqueous solutions up to high temperatures and high pressures:

Albert, H.J., Wood, R.H.: High-precision flow densimeter for fluids at temperatures to $700 \mathrm{~K}$ and pressures to $40 \mathrm{MPa}$. Rev. Sci. Instrum. 55, 589-593 (1984).

- Heat capacity measurements on aqueous solutions up to high temperatures and high pressures:

Biggerstaff, D.R., Wood, R.H.: Apparent molar heat capacities of aqueous argon, ethylene, and xenon at temperatures up to $720 \mathrm{~K}$ and pressures to $33 \mathrm{MPa}$. J. Phys. Chem. 92, 1994-2000 (1988).

Hnedkovsky, L., Majer, V., Wood, R.H.: Volumes and heat capacities of $\mathrm{H}_{3} \mathrm{BO}_{3}(\mathrm{aq})$ at temperatures from $298.15 \mathrm{~K}$ to $705 \mathrm{~K}$ and at pressures to $35 \mathrm{MPa}$. J. Chem. Thermodyn. 27, 801-814 (1995).

- Conductance measurements on aqueous electrolytes up to high temperatures and high pressures:

Zimmerman, G.H., Wood, R.H.: Conductance of dilute sodium acetate solutions to $469 \mathrm{~K}$ and of acetic acid and sodium acetate/acetic acid mixtures to $548 \mathrm{~K}$ and 20 MPa. J. Solution Chem. 31, 995-1017 (2002).

- Semi-empirical equations of state:

Plyasunov, A.V., O'Connell, J.P., Wood, R.H., Shock, E.L.: Semiempirical equation of state for the infinite dilution thermodynamic functions of hydration of nonelectrolytes over wide ranges of temperature and pressure. Fluid Phase Equilib. 183-184, 133-142 (2001).

Plyasunov, A.V., Shock, E.L., Wood, R.H.: Second cross virial coefficients for interactions involving water. Correlations and group contribution values. J. Chem. Eng. Data 48, 1463-1470 (2003).

Myers, J.A., Sandler, S.I., Wood, R.H.: An equation of state for electrolyte solutions covering wide ranges of temperature, pressure, and composition. Ind. Eng. Chem. Res. 41, 3282-3297 (2002).

Sedlbauer, J., Wood, R.H.: Thermodynamic properties of dilute $\mathrm{NaCl}(\mathrm{aq})$ solutions near the critical point of water. J. Phys. Chem. B 108, 11838-11849 (2004).

- Theoretical predictions of structure and free energy:

Sakane, S., Liu, W., Doren, D.J., Shock, E.L., Wood, R.H.: Prediction of the Gibbs energies and an improved equation of state for water at extreme conditions from ab initio energies with classical simulations. Geochim. Cosmochim. Acta 65, 4067-4075 (2001).

Yezdimer, E.M., Wood, R.H.: Problems with some current water models for close pair interactions that are not near the minimum energy. J. Chem. Theory Comput. 6, 438-442 (2010).

- Hydrophobic interactions:

Wood, R.H., Thompson, P.T.: Differences between pair and bulk hydrophobic interactions. PNAS 87, 946-949 (1990).

As indicated by these representative publications, Professor Wood always tries to keep a reasonable balance between more theoretical problems and well-designed experimental work; during his active career, this approach has attracted more than 160 students and collaborators who deeply appreciated, and still do, this attitude!

Looking back to the early years of designing and building, and re-designing and rebuilding flow densimeters and flow calorimeters, we note that Professor Wood's decisive advances were essentially based on the realization that if experiments were made on a 
flowing fluid stream (with no vapor phase) inside a metal tube of small diameter, rapid temperature equilibration and hence rapid measurements could be achieved. Furthermore, since for each new measurement a new solution would be pumped in from outside of the apparatus, the low residence time would bring about low corrosion and low decomposition. The instruments finally developed made possible pioneering measurements of the density and the heat capacity of (dilute) aqueous solutions of nonelectrolytes as well as electrolytes from ambient temperatures to the critical temperature of the solvent water $\left(T_{\mathrm{c}}=647.1 \mathrm{~K}\right)$ and beyond, well into the single fluid region. This versatile methodology may be applied in exploratory experiments as well as in systematic investigations. Bob's care and perseverance in building state-of-the-art apparatus for measurements nobody had been able to make before, has brought about an extraordinary rich scientific harvest as evidenced, for instance, by the selected experimental results presented above. Since experiments become more difficult and less accurate at elevated temperatures and pressures, valuable semiempirical prediction methods were developed incorporating a group additivity approach.

Professor Wood's research efforts may perhaps best be described by a phrase used in the title sequence of most episodes of the original Star Trek science fiction television series:

\section{To Boldly Go Where No Man has Gone Before}

As a consequence, the scientific community acknowledged and honored his pioneering achievements with three prestigious awards:

- In 1988 he was the first recipient of the James J. Christensen Memorial Award of the Calorimetry Conference. At the 43rd Calorimetry Conference he delivered an award lecture entitled

Flow calorimetry and densimetry at high temperatures

The Christensen Award is presented to a scientist in recognition of outstanding innovative contributions to the development and use of calorimetric instrumentation.

- In 1993 he was the recipient of the Hugh M. Huffman Memorial Award of the Calorimetry Conference. At the 48th Calorimetry Conference he delivered an award lecture entitled

Aqueous electrolytes at high temperature: theory and experiment

The Huffman Award is presented to a scientist in recognition of long-term contributions to thermodynamics involving calorimetry and/or thermochemistry.

- In 2004 he was the second recipient, after Professor E. U. Franck, of the Gibbs Award of the International Association for the Properties of Water and Steam (IAPWS). At the 14th International Conference on the Properties of Water and Steam (ICPWS) he delivered an award lecture entitled

Adventures in high temperature aqueous solutions: theory and experiments

The Gibbs Award is presented to a distinguished scientist or engineer in recognition of substantial contributions to the development of knowledge on the properties of water, steam and aqueous solutions at high temperatures and pressures, as well as to other areas of underlying science and technology of interest to IAPWS.

I first met Bob at the 26th Calorimetry Conference and 2nd International Conference on Chemical Thermodynamics (IUPAC) in Orono, ME, USA, 12-14 July 1971, and since then I had the pleasure to meet him on many occasions at international conferences, at the University of Delaware in Newark, DE, USA, at the University of Wien (Vienna) in Wien (Vienna), Austria, and, perhaps most enjoyable, during leaves of absence in ClermontFerrand, France, at Professor Jean-Pierre E. Grolier's home university (named after the 
great French mathematician, physicist and philosopher Blaise Pascal). In fact, both Professor Wood and I received an honorary doctorate from this university.

For the foreseeable future, Bob's contributions to physical chemistry in general, and to solution thermodynamics in particular, represent a legacy of exciting scientific results. It is a pleasure to dedicate this special issue as a Festschrift of the Journal of Solution Chemistry to Professor Robert H. Wood, and I wish him well in all his future endeavors. 